\title{
Influence of valve prosthesis type on early mortality in patients undergoing valve surgery
}

\author{
A influência da escolha da prótese valvar sobre a mortalidade intra-hospitalar no pós-operatório em \\ pacientes submetidos à cirurgia valvar
}

\author{
André Mauricio S. Fernandes ${ }^{1}, \mathrm{MD}, \mathrm{MsC}$; Felipe da Silva Pereira ${ }^{1}$; Larissa Santana Bitencourt ${ }^{1}$, \\ MD; Agnaldo Viana Pereira Neto ${ }^{1}$, MD; Gabriel Barreto Bastos ${ }^{1}$; André Rodrigues Durães ${ }^{1}$, MD, \\ PhD; Roque Aras Jr${ }^{1}$, MD, PhD; Igor Nogueira Lessa ${ }^{1}, \mathrm{MD}$
}

\section{Abstract}

Objective: To evaluate the influence of the type of prosthesis in-hospital mortality in the post-operative period in patients who had valve replacement.

Methods: A cross-sectional data, such as gender, origin, age, etiology, echocardiograph data, the type of surgery performed and the prosthesis used in cases of valve replacement were analyzed retrospectively.

Results: We reviewed 353 charts of patients who underwent valve replacement surgery. The mean age was 41.87 \pm 17.9 years. Regarding gender, $\mathbf{5 2 . 8 \%}$ were female. As for the origin, $61.1 \%$ came from small cities within the state. Of all patients, $58.5 \%$ suffered from rheumatic disease. Assessing the type of prosthesis implanted, $70 \%$ held replace by bioprosthesis and $30 \%$ metallic. The hospital mortality in this study was $11 \%$, with no significant difference between the types of prosthesis utilized.

Conclusion: The type of implant used had no effect on in-hospital mortality.

Descriptors: Mortality. Heart Valve Diseases. Heart Valve Prosthesis.

\section{Resumo}

Objetivo: Avaliar a influência do tipo de prótese na mortalidade intra-hospitalar no período de pós-operatório imediato nos pacientes que fizeram substituição de válvula.

Métodos: Estudo transversal, em que dados, como sexo, origem, idade, etiologia, dados ecocardiográficos, o tipo de cirurgia realizada e da prótese utilizada em casos de substituição de válvula foram analisadas retrospectivamente.

Resultados: Foram revisados 353 prontuários de pacientes que realizaram cirurgia de troca valvar. A idade média foi de $41,87 \pm 17,9$ anos. Em relação ao gênero, $52,8 \%$ eram do sexo feminino. Quanto à origem, $61,1 \%$ vieram de cidades do interior do estado. Do total de pacientes, $58,5 \%$ eram portadores da doença reumática. Avaliando o tipo de prótese implantada, $\mathbf{7 0} \%$ realizou troca por bioprótese e $\mathbf{3 0 \%}$ metálica. A mortalidade hospitalar desse estudo foi de $11 \%$, não havendo diferença significativa entre o tipo de prótese utilizada.

Conclusão: $O$ tipo de prótese utilizada não influenciou na mortalidade intra-hospitalar.

Descritores: Mortalidade. Doenças das Valvas Cardíacas. Próteses Valvulares Cardíacas.
${ }^{1}$ Hospital Ana Nery (HAN), Salvador, BA, Brazil.

This study was carried out at Hospital Ana Nery (HAN), Salvador, BA, Brazil.

No financial support
Article received on August $20^{\text {th }}, 2013$ Article accepted on December $11^{\text {th }}, 2013$ 


\begin{tabular}{|ll|}
\hline Abbreviations, acronyms and symbols \\
\hline MS & Ministry of Health (acronym in Portuguese) \\
RD & Rheumatic Disease \\
SD & Standard Deviation \\
SPSS & Statistical Package for the Social Sciences \\
\hline
\end{tabular}

\section{INTRODUCTION}

Valvular heart disease is a major public health problem. Since the $50 \mathrm{~s}$, the prevalence of valve disease in developed countries has been varying from rheumatic etiology to degenerative valve disease ${ }^{[1]}$. In the early twentieth century, rheumatic disease (RD) was a major cause of morbidity and mortality among young people in developed and developing countries ${ }^{[2,3]}$, affecting them in a similar way. This pattern changed due to several factors, including early diagnosis, appropriate treatment of RD and also due to increased life expetancy leading to valve disease in older individuals.

Rheumatic disease, even nowadays, has a high prevalence in developing countries such as Brazil, which is an important cause of cardiovascular disease and is responsible for high costs to the public health system. According to data provided by MS, during the year 2011, there were 5,512 hospital admissions due to acute rheumatic fever and 8,127 presenting with rheumatic valvular disease ${ }^{[4]}$.

The postoperative in-hospital mortality rate is very variable, mostly due to the severity of hospitalized patients and the degree of experience of the surgical team. According to other studies, the mortality rate varies between $1 \%$ and $15 \%^{[1,5-8]}$. After 40 years of experience with valve replacement surgery in the country, the decision by the most appropriate type of prosthesis to be implanted in surgery is still controversial and sometimes complicated, especially for patients coming from rural areas or small towns.

There is not an ideal substitute. There is a low risk of thromboembolic events and bleeding in the use of bioprosthesis, but its durability is short. On the other hand, the metallic prosthesis may offer longer duration, but with greater risk for such events ${ }^{[9]}$. Marchand et al. ${ }^{[10]}$ and MyKen et al. ${ }^{[1]}$ demonstrated satisfactory progress in the survival of patients after 14 and 15 years, respectively, bioprosthesis structural dysfunction free in both atrioventricular and aortic site.
There are few studies evaluating the mortality in patients with heart valve disease. The focus of this study is to evaluate the impact of the choice of prosthesis on in-hospital mortality rate in patients with rheumatic and non-rheumatic heart disease who underwent surgical valve replacement.

\section{METHODS}

Analytical cross-sectional study with convenience sampling of patients who underwent valve replacement surgery during a period of three years at Ana Nery Hospital, Salvador, Bahia, Brazil.

All data were obtained from medical records. Data analysis was performed based on the guidelines for reporting morbidity and mortality after cardiac valve interventions ${ }^{[9]}$. Thirty-five patients were excluded for lack of recorded data; thus, the total sample was 353 .

Data were analyzed using SPSS version 17.0. Continuous variables had their normality tested with the Kolmogorov-Smirnov test. To compare the means, the T test was used for normally distributed variables. The chi-square test was used to compare categorical variables. The $\mathrm{p}$ value adopted as statistically significant was $P \leq 0.05$. The project was approved by the Ethics Committee of Ana Nery Hospital under the $59 / 10$ protocol.

\section{RESULTS}

The total sample studied was 353 patients undergoing valve replacement surgery, and 73 of these were submitted to valve replacement and valvuloplasty. The male sex represented $49.6 \%(n=175)$ of them and $50.4 \%(n=178)$ were female. The age of the study population ranged from 6 to 82 years and the average age was $41.87 \pm 17.9$ years. We observed a greater number of individuals from the contryside or rural areas $(n=216,61.2 \%)$ compared to the capital $(\mathrm{n}=137,38.8 \%)$ (demographic data - Table 1). We also observed a total of 698 affected valves, $282(40.4 \%)$ were mitral, 214 (30.7\%) aortic, 183 (26.2\%) tricuspid and 19 (2.7\%) were pulmonary valves. Among them, 53 (7.6\%) showed stenosis, 461 (66\%) had insufficiency and 184 (26.4\%) had double lesion.

The patients were also divided according to their main mechanism of valve lesion: 204 (57.8\%) had rheumatic disease as the main cause for valve disease and 134 (38\%) had valvular disease due to other causes, such as prolapse, secondary to ischemia or degenerative disease, and 15 (4.2\%) had no definite etiology.

Regarding the type of prosthesis used, $70 \%(\mathrm{n}=247)$ were replaced by bioprosthesis and $30 \%(\mathrm{n}=106)$ by metal prosthesis. The preference to use bioprostheses was observed in all age groups (Figure 1). 
Table 1. Demographics

\begin{tabular}{lcc}
\hline Classification & $\mathrm{N}$ & $\%$ \\
\hline Gender & 175 & 49.6 \\
Male & 178 & 50.4 \\
Female & & \\
Age & 40 & 11.3 \\
$0-20$ years & 68 & 19.3 \\
21-30 years & 53 & 15 \\
31-40 years & 74 & 21 \\
41-50 years & 50 & 14.2 \\
51-60 years & 68 & 19.2 \\
$>$ 60 years & & \\
Etiology of valvular heart disease & 204 & 57.8 \\
Rheumatic disease & 134 & 38 \\
Non-rheumatic disease & 15 & 4.2 \\
Lost data & & \\
Prosthesis & 247 & 70 \\
Bioprosthesis & 106 & 30 \\
Metallic prosthesis & & \\
Affected valve & 194 & 55 \\
Mitral valve & 98 & 27.8 \\
Aortic valve & 61 & 17.2 \\
Mitral and aortic valve & & \\
\hline
\end{tabular}

The overall mortality was $11 \%(n=39)$, and we did not observe difference between the type of prosthesis on overall mortality. The mortality caused by mechanical valve in comparison with bioprosthesis was $30.7 \%(n=12) \times 69.3 \%$ $(\mathrm{n}=27)$, respectively, $P=0.915$. When analyzing only patients with rheumatic disease, we could not also observe a statistically significant difference in mortality rates between the metal prosthesis $x$ bioprosthesis, $33.3 \%(n=3) \times 66.7 \%(n=6)$, respectively, $P=0.586$.

The mean age \pm SD for the patients who died was $54.49 \pm 21.9$ years, versus $41.19 \pm 16.8$ years of those who were discharged, $P=0.000$ (Figure 2).

Among the patients who died, 33 were submitted to only one valve replacement. Therefore, there was no impact of the double valve replacement on mortality. In relation to the location of valve replacement surgery, the results are shown in Figure 3.

\section{DISCUSSION}

There was a high prevalence of rheumatic valve disease $(58.5 \%)$ in this study, and these data are consistent with previous data on rheumatic disease, which is a major cause of heart disease in developing countries ${ }^{[10]}$. There was no effect on mortality regarding the type of implant used in valve replacement surgery.

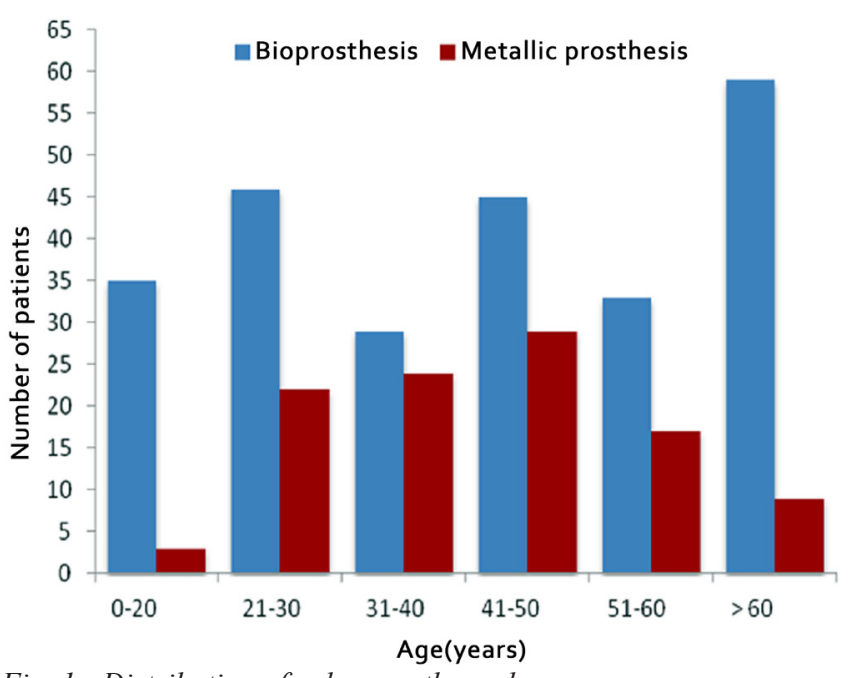

Fig. 1 - Distribution of valve prostheses by age.

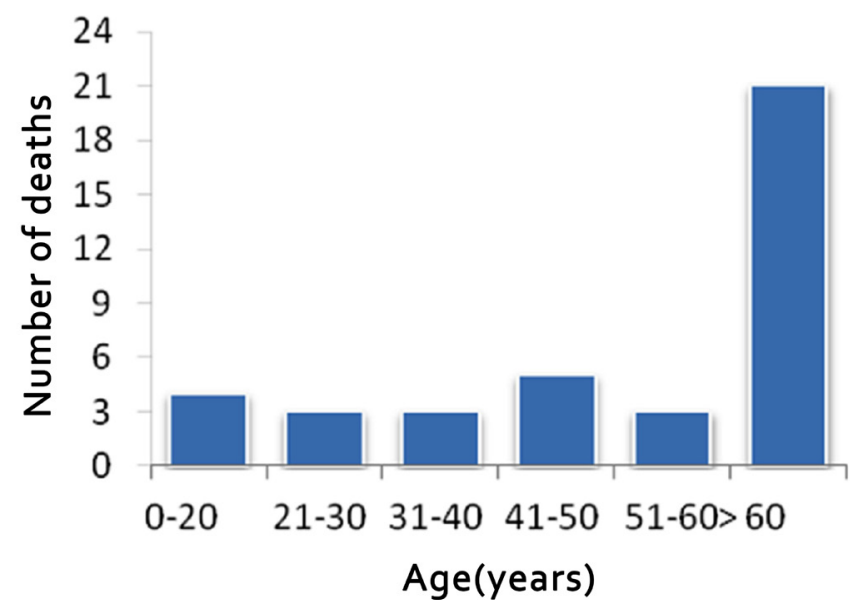

Fig. 2 - Number of deaths vs. Age group.

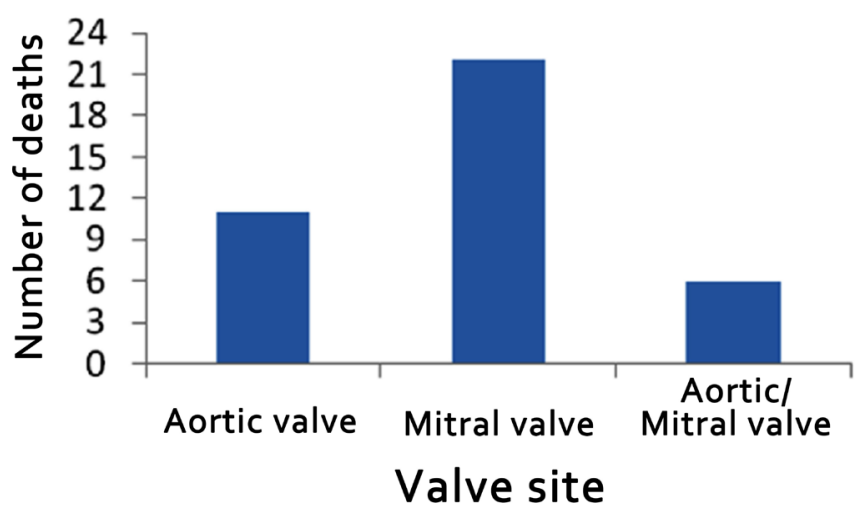

Fig. 3 - Number of deaths vs. Valve site. 
The postoperative mortality rate is very variable and is influenced by many factors, such as multiple replacement valve, affected site, reoperation and presence of other associated procedures. This study demonstrated a $10.6 \%$ mortality rate, which is in agreement with the literature data ranging from $1 \%$ to $15 \%{ }^{[12,13]}$. The average age of patients who died was $54.4 \pm 21.5$ years, higher than the total study sample ( $40.40 \pm 16.8$ years), $P=0.001$. This difference is probably due to valves with more severe lesions, associated or not with higher presence of comorbidities in older population, since there was no association between the type of prosthesis and mortality when age was taken into consideration.

Patients who underwent mitral valve replacement had a higher mortality, regardless of the type of prosthesis used. This finding is consistent with what is reported in the literature $^{[7,14,15]}$.

The impact of the choice of valve prosthesis for patients who have rheumatic etiology has not been established. The use of bioprosthesis in this population influences the late mortality, since it may be a new procedure after a few years, a previous study shows mortality similar to the first surgery $(1 \% \text { to } 15 \%)^{[16]}$. However, Cen et al. ${ }^{[17]}$ published in 2001 that the choice of the type of implanted prosthesis did not statistically interfere in survival of patients undergoing valve replacement in 10 years.

In our study, we observed that victims of rheumatic sequel were young adults, especially women, resulting in socio-economic repercussions as increased costs of public health and the reduction of labor input.

This study shows that the most frequent injury was the valve regurgitation $(66.2 \%)$ followed by double lesion $(25.9 \%)$ and stenosis $(7.9 \%)$, in disagreement with the literature where it is shown a prevalence of stenotic lesions . However, this is a difficult comparison to make due to the scarcity of data on the prevalence of specific lesions, especially in rheumatic disease ${ }^{[18]}$.

It is generally very difficult to assess these patients due to poor adherence to treatment, since their families need to take long trips, dealing with cost of food and stay, in a scenario of a limited family budget. Unfortunately, this is a negative milestone for the treatment with impact on the choice of the prosthesis and possible consequences for a later outcome ${ }^{[19]}$. The higher prevalence of bioprosthesis in the present study can be justified by the large number of countryside patients without adequate specialized medical services, a fact that often leads to poor adherence to treatment and prevent the institution from anticoagulant therapy.

The type of prosthesis did not have influence on in-hospital mortality in the study population, however, it can be considered an important prognostic factor for late mortality in patients suffering from valvular diseases with high prevalence of rheumatic etiology. Therefore, cohort studies with similar populations, especially in developing countries, should be encouraged.

\begin{tabular}{|ll|}
\hline \multicolumn{2}{|l|}{ Authors' } \\
\hline AMSF & M responsibilities \\
FSP & Main author \\
LSB & Co-author, collection of material, statistical analysis \\
AVPN & Co-author \\
GBB & Medical record survey, collection of material, co-author \\
ARD & Co-author, references research \\
RAJ & Co-author, references research \\
INL & Co-author, references research \\
\hline
\end{tabular}

\section{REFERENCES}

1. Iung B, Vahanian A. Epidemiology of valvular heart disease in the adult. Nat Rev Cardiol. 2011;8(3):162-72.

2. Soler-Soler J, Galve E. Worldwide perspective of valve disease. Heart. 2000;83(6):721-5.

3. Vahanian A, Baumgartner H, Bax J, Butchart E, Dion R, Filippatos G, et al; Grupo de Trabajo sobre el Tratamiento de las Valvulopatías de la Sociedad Europea de Cardiología. Guidelines on the management of valvular heart disease. Rev Esp Cardiol. 2007;60(6):1e-50e.

4. Brasil. Ministério da Saúde. DATASUS. Informações de Saúde. Mortalidade, 2011. Brasília: Ministério da Saúde;2012.

5. Feguri GR, Macruz H, Bulhões D, Neves A, Castro RM, Fonseca $\mathrm{L}$, et al. Aortic valve replacement with different types of prosthesis: are there differences in the outcomes during hospital phase? Rev Bras Cir Cardiovasc. 2008;23(4):534-41.

6. Almeida AS, Picon PD, Wender OC. Outcomes of patients subject to aortic valve replacement surgery using mechanical or biological prostheses. Rev Bras Cir Cardiovasc. 2012;26(3):326-37.

7. Stassano P, Di Tommaso L, Monaco M, Iorio F, Pepino P, Spampinato $\mathrm{N}$, et al. Aortic valve replacement: a prospective randomized evaluation of mechanical versus biological valves in patients ages 55 to 70 years. J Am Coll Cardiol. 2009;54(20):1862-8.

8. Astor BC, Kaczmarek RG, Hefflin B, Daley WR. Mortality after aortic valve replacement: results from a nationally representative database. Ann Thorac Surg. 2000;70(6):1939-45.

9. Pomerantzeff PM, Brandão CM, Cauduro P, Puig LB, Grinberg M, Tarasoutchi F, et al. Fisics-Incor bovine pericardial bioprostheses: 15 year results. Heart Surg Forum. 1998;1(2):130-5. 
10. Marchand MA, Aupart MR, Norton R, Goldsmith IR, Pelletier LC, Pellerin M, et al. Fifteen-year experience with the mitral Carpentier-Edwards PERIMOUNT pericardial bioprosthesis. Ann Thorac Surg. 2001;71(5 Suppl):S236-9.

11. Mykén P, Bech-Hanssen O, Phipps B, Caidahl K. Fifteen years follow up with the St. Jude Medical Biocor porcine bioprosthesis. J Heart Valve Dis. 2000;9(3):415-22.

12. Pomerantzeff PM, Barbosa GV, de Sousa Filho BS, Brandão CM, Ribeiro EJ, Costa FD, et al. Guidelines for surgery in heart valve diseases. Arq Bras Cardiol. 2004;82(Suppl 5):22-33.

13. Bottio T, Rizzoli G, Caprili L, Testolin L, Thiene G, Gerosa G. Biological versus mechanical aortic prosthesis? A nineteen-year comparison in a propensity-matched population. J Heart Valve Dis. 2005;14(4):493-500.

14. Filsoufi F, Chikwe J, Castillo JG, Rahmanian PB, Vassalotti J, Adams DH. Prosthesis type has minimal impact on survival after valve surgery in patients with moderate to end-stage renal failure. Nephrol Dial Transplant. 2008;23(11):3613-21.
15. Silberman S, Oren A, Dotan M, Merin O, Fink D, Deeb M, et al. Aortic valve replacement: choice between mechanical valves and bioprostheses. J Card Surg. 2008;23(4):299-306.

16. Brandão CMA, Pomerantzeff PMA, Souza LR, Tarasoutchi F, Grimberg M, Oliveira SA. Fatores de risco para mortalidade hospitalar nas reoperações valvares. Rev Bras Cir Cardiovasc. $2002 ; 17(3): 236-41$.

17. Cen YY, Glower DD, Landolfo K, Lowe JE, Davis RD, Wolfe $\mathrm{WG}$, et al. Comparison of survival after mitral valve replacement with biologic and mechanical valves in 1139 patients. J Thorac Cardiovasc Surg. 2001;122(3):569-77.

18. Fernandes AM, Bitencourt LS, Lessa IN, Viana A, Pereira F, Bastos G, et al. Impact of socio-economic profile on the prosthesis type choice used on heart surgery. Rev Bras Cir Cardiovasc. 2012;27(2):211-6.

19. Gus I, Zaslavsky C, Seger JM, Strehl Machado R. Epidemiology of rheumatic fever. A local study. Arq Bras Cardiol. 1995;65(4):321-5. 